\title{
PENAMBANGAN TIMAH DI INDONESIA: SEJARAH, MASA KINI, DAN PROSPEKSI
}

\author{
Tin Mining in Indonesia: History, Current Status, and Future Prospect
}

\author{
RONALDO IRZON \\ Pusat Survei Geologi, \\ Jalan Diponegoro 57, Bandung, \\ e-mail : ronaldoirzon18@gmail.com
}

\begin{abstract}
ABSTRAK
Indonesia telah menjadi penghasil timah besar dunia sejak awal abad ke-20. Sumberdaya tersebut berasosiasi dengan Sabuk Timah Asia Tenggara yang membentang melalui Sumatra, kepulauan di timur Sumatra, dan bagian barat Kalimantan. Penambangan timah telah banyak menghasilkan devisa negara namun juga dapat merusak lingkungan jika tidak direncanakan dan dikelola dengan baik. Tulisan ini membahas penambangan logam timah di Indonesia pada masa lalu, keadaan terkini, dan peluangnya pada masa mendatang agar menjadi salah satu referensi untuk pembuatan kebijakan strategis bagi pemerintah maupun perusahaan penambangan timah. Metode yang digunakan dalam studi ini adalah metode kualitatif deskriptif yaitu pengungkapan peristiwa penambangan timah dengan menjabarkan keadaannya berdasarkan fakta yang ada. Hindia Belanda termasuk ke dalam negara pencetus International Tin Agreement (ITA) hingga pembentukan International Tin Council (ITC) untuk menstabilkan harga timah. Namun demikian, kegagalan ITA ke-6, ledakan hutang ITC, dan penggunaan bahan substitusi diprediksi sebagai penyebab utama kemerosotan harga timah pada pertengahan 1980-an. PT Timah Tbk sebagai penggabungan tiga perusahaan timah bentukan Hindia Belanda dapat terus menjadi tiga besar perusahaan penambangan timah dunia selama satu dekade terakhir dengan strategi pengalihan konsentrasi eksploitasi dari darat ke laut dan proses daur ulang. Besaran pendapatan dari penambangan timah saat ini terutama dipengaruhi oleh jumlah produksi, harga pasar, nilai tukar dolar, dan hubungan bilateral IndonesiaCina. Meskipun harga timah kembali jatuh akibat wabah Covid-19 sejak awal tahun 2020, logam ini diperkirakan masih mejadi komoditas penting pada masa mendatang dengan proyeksi harga yang semakin meningkat. Pengolahan mineral ikutan timah merupakan sumber pendapatan prospektif berikutnya selain juga untuk memperkecil dampak lingkungan akibat kegiatan pertambangan.
\end{abstract}

Kata kunci: penambangan timah, Indonesia, produksi, harga, prospeksi.

\begin{abstract}
Indonesia is a major world tin producer since the beginning of the 20th century. The tin resource is associated with the Southeast Asian Tin Belt which extends through Sumatra, the islands at the east of Sumatra, and western Borneo. Tin mining has generated a lot of revenue for this country but might also damage the environment if it is not planned and managed properly. This paper discusses tin mining in Indonesia during the past, current conditions, and opportunities in the future in order to become a reference for the government's and tin mining companies' strategic policy. This study uses a descriptive qualitative method of events associated with tin mining by describing the situation based on existing facts. The Dutch East Indies was one of the International Tin Agreement (ITA) and International Tin Council (ITC) founding countries on stabilizing the tin price. However, the failure of the 6th ITA, ITC's huge debt, and the use of substitute materials were the main factors of the price crash in the mid-1980s. PT Timah Tbk as a merger of three companies formed by the Dutch East Indies is successful to be the top three world tin mining companies for the last decade by shifting the exploitation focus from land to offshore and adapting recycling process. Revenue from tin mining is currently influenced by the production, market price, rupiah-dollar exchange rate, and Indonesia-China bilateral relation. Although the price of tin declines due to the Covid-19 since the
\end{abstract}


beginning of 2020, this metal would be an important commodity in the future with increasing price projection. The processing of tin associated minerals is another prospective source of income and minimize the environmental impact of mining activities.

Keywords: tin mining, Indonesia, production, price, future prospect.

\section{PENDAHULUAN}

Mineralisasi timah di Indonesia merupakan topik yang menarik karena hanya terdapat di bagian barat Nusantara, yaitu pada Sabuk Timah Asia Tenggara yang membentang dari Myanmar, Thailand, Malaysia, jajaran kepulauan timah di timur Sumatra, hingga barat Kalimantan (Irzon dkk., 2014; Irzon, 2017; Breitfeld dkk., 2020; Wicaksono dan Handayani, 2021). Sebagian besar deposit timah tersebut sangat berasosiasi dengan intrusi batuan granitik Tersier yang terdapat di Semenanjung Malaysia, Karimun, Kundur, Singkep, Bangka, dan Belitung (Gambar 1). PT. Timah Tbk saat ini menjadi perusahaan terbesar yang melakukan eksplorasi, eksploitasi, dan pengolahan di Kepulauan Timah Indonesia. Deposit timah juga dilaporkan terdapat di Pulau Sumatra, yaitu di Hatapang, Pegunungan Tigapuluh, dan Bakinang (Clarke dan Beddoe-Stephens, 1987; Johari dan Umi, 1991). Indonesia memiliki sejarah penambangan timah yang panjang dan saat ini merupakan penghasil timah terbesar kedua dunia setelah Cina.
Keberadaan timah juga memiliki imbas terhadap kondisi ekonomi dan sosial masyarakat. Penambangan timah yang dimulai sejak periode kolonialisme tentu telah banyak membuka lapangan kerja. Penjualan timah juga telah mendatangkan devisa baik untuk pemerintah Hindia-Belanda pada masa kolonial maupun pemerintah Indonesia setelah masa kemerdekaan (Rosyida $d k k$., 2019; Syahrir, Wall dan Diallo, 2020). Asimilasi antara imigran Cina yang didatangkan oleh pemerintah Hinda-Belanda dengan penduduk setempat juga disebabkan oleh penambangan timah. Pada sisi lain, kerusakan lingkungan berupa polusi logam berat, erosi, kehilangan keanekaragaman hayati, vegetasi, dan perubahan struktur muka bumi berkaitan dengan kegiatan penambangan (Irzon, 2018; Irzon $d k k$., 2018; Syahrir, Wall dan Diallo, 2020). Oleh sebab itu, kegiatan penambangan harus direncanakan dengan baik untuk meminimalkan dampak lingkungannya.

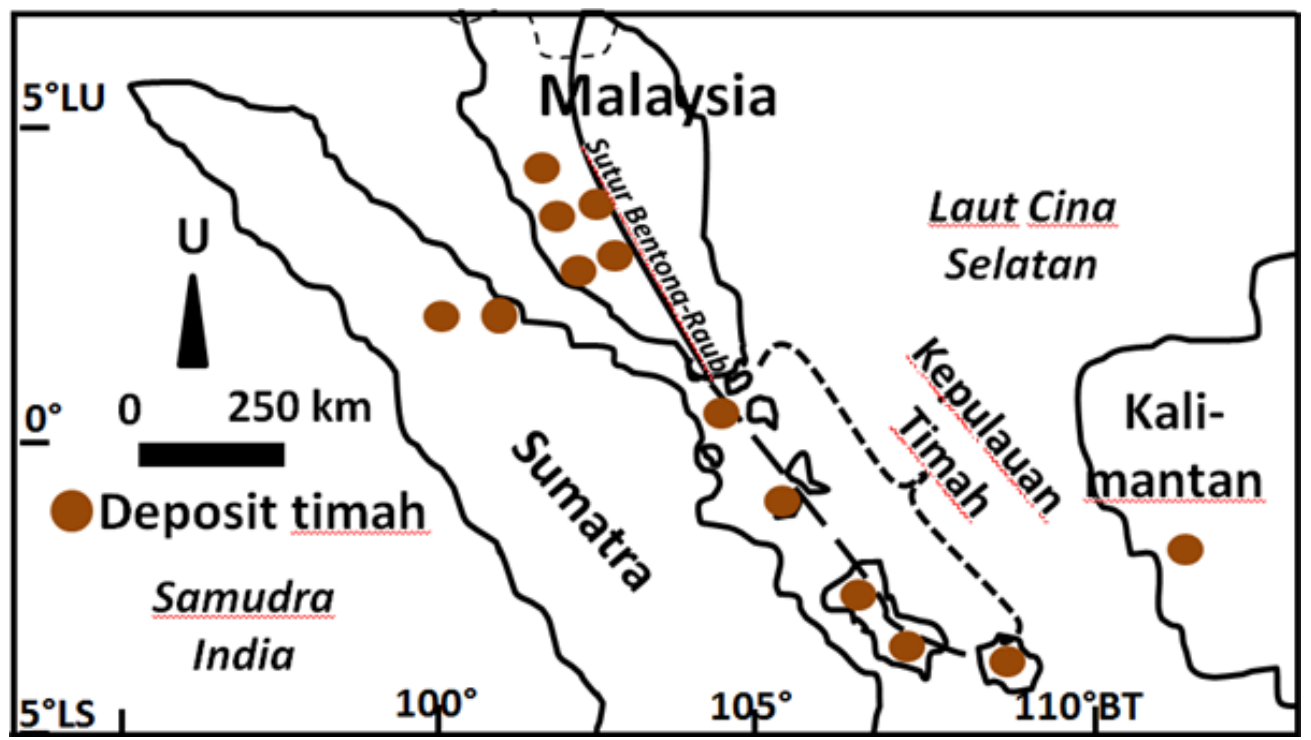

Gambar 1. Deposit timah di Indonesia dan Semenanjung Malaysia (Clarke dan Beddoe-Stephens, 1987; Johari dan Umi, 1991; Irzon dkk., 2014; Yang dkk., 2018) 
Ragam sumberdaya yang terdapat di bumi Indonesia harus memperkuat perekonomian nasional sehingga dapat mendorong kesejahteraan rakyat seperti yang tertuang dalam pasal 33 UUD 1945. Oleh sebab itu, perlu dilakukan riset dari hulu hingga ke hilir agar diperoleh pemetaan, skema eksploitasi, pengolahan, pemasaran, dan penanganan dampak lingkungan yang baik terkait dengan sumberdaya tadi. Studi ini membahas kondisi komoditas timah di Indonesia meliputi kondisi pada masa lampau, keadaan terkini, dan peluang terkait pertambangan pada masa mendatang. Hasil penelitian dapat dijadikan referensi untuk pembuatan kebijakan strategis bagi pemerintah maupun perusahaan penambangan timah.

\section{METODE}

Penelitian kualitatif bertujuan untuk menangkap makna terdalam atas suatu peristiwa, gejala, fakta, maupun masalah tertentu tanpa pembuktian adanya hubungan sebab akibat atau korelasi dari suatu masalah atau peristiwa. Pada sisi lain, kaidah penelitian kuantitatif cenderung didasarkan kepada ukuran numerik daripada aspek gejala yang khusus. Metode deskriptif dilaksanakan untuk mengetahui gambaran, keadaan suatu hal dengan cara mendeskripsikannya sedetail mungkin berdasarkan fakta yang ada. Studi ini berjenis kualitatif deskriptif yaitu pengungkapan peristiwa penambangan timah dengan menjabarkan keadaannya berdasarkan fakta yang ada.

Data mengenai produksi, harga jual, cadangan, dan kebijakan mengenai penambangan timah di Indonesia dari berbagai sumber dikumpulkan, disarikan, dan dibahas dalam tulisan ini. Dokumen dari International Tin Association (ITA) dan United States Geological Survey (USGS) digunakan untuk pembahasan kondisi pasar timah pada abad ke-20. Data PT Timah Tbk bermanfaat untuk analisis situasi penambangan timah, terutama nasional, pada dekade terakhir. Hasil-hasil penelitian sebelumnya maupun data dari situs pertambangan dipergunakan untuk prediksi kondisi dan harga timah dulu hingga masa mendatang.

\section{SEJARAH PENAMBANGAN TIMAH}

\section{Proses Mineralisasi Timah}

Timah (Sn) merupakan unsur dengan berat atom 118,71 dan nomor atom 50. Kelimpahan logam ini di kerak bumi adalah 2 ppm. Titik leburnya yang cukup rendah (232 $\left.{ }^{\circ} \mathrm{C}\right)$ sehingga mudah dilelehkan dan dilebur adalah penyebab timah telah lama dimanfaatkan oleh manusia, yaitu sejak 3.500 SM (Kinnaird, Nex dan Milani, 2016). Karakter tersebut membuat timah mudah dipadukan dengan tembaga untuk membuat perangkat bagi keperluan berburu, berperang, dan rumah tangga. Selain itu logam timah bersifat mengkilap dan tidak mudah teroksidasi sehingga tahan karat. Berdasarkan prasasti Kotakapur di muara sungai Mendu wilayah Bangka Barat, timah diperkirakan telah mulai dipergunakan oleh masyarakat Indonesia sejak abad ke-7. Mineral mengandung timah terdapat dari deposit primer yang berada dalam batuan dan sekunder sebagai hasil pelapukan-erosi dari batuan pembawa timah. Akibat keterbatasan perangkat penambangan, timah sekunder pada deposit aluvial lebih dulu dimanfaatkan oleh manusia (Powell $d k k$., 2021).

Keterdapatan deposit timah primer dipengaruhi oleh beberapa faktor, yaitu tipe batuan, kondisi oksidasi, dan derajat fraksionasi. Timah adalah logam inkompatibel yang sensitif terhadap kondisi redoks. Sn semakin terkonsentrasikan pada kondisi reduksi dan sangat terfraksionasi yang terjadi pada magma yang telah sangat berevolusi (Cheng $d k k$., 2018; Qu dkk., 2020). Batuan granitik adalah jenis batuan felsik dan secara umum dikelompokkan menjadi tipe-I, S, -A, dan -M. Karena terbentuk dari pelelehan kembali kerak bumi, Granit tipe-S secara umum telah lebih jauh mengalami evolusi, tereduksi, dan mengandung $\mathrm{SiO}_{2}$ lebih tinggi bila dibandingkan tipe-I dan -M. Oleh sebab itu, mineralisasi timah banyak berasosiasi dengan granit tipe-S seperti yang terdapat pada Sabuk Granit Asia Tenggara. Meski demikian, Pollard, Nakapadungrat dan Taylor (1995) serta Qiu dkk. (2017) melaporkan deposit timah pada granit tipe-I yang terfraksionasi di Phuket (Thailand) dan Jinkeng (China). 
Kasiterit $\left(\mathrm{SnO}_{2}\right)$ adalah mineral utama timah. Mineral ini pada umumnya berwarna coklat gelap, meski juga ditemukan yang berwarna kemerahan dan kekuningan akibat variasi kandungan unsur jejaknya. Terdapat setidaknya 14 mineral pembawa timah lainnya dan beberapa hanya ditemukan pada wilayah tertentu. Abhurit, nigerit, dan malayait masing-masing hanya terdapat di Sharm Abhur, Nigeria, dan semenanjung Malaya secara berurutan. Nigerit kini dikenal sebagai Ferronigerite-2N1S (Cairncross, 2020).

\section{Riwayat Penambangan Timah di Indonesia}

Meskipun awal mula pemanfaatan timah di Indonesia didasarkan pada situs Kota Kapur seperti diterangkan sebelumnya, tidak ditemukan bukti penggalian timah secara massal hingga tahun 1709 di Toboali (Pulau Bangka) oleh pekerja dari Johor, Malaysia (Suprapto, 2008). Pada masa itu, timah terutama dimanfaatkan untuk pembuatan uang koin. Pada masa kolonial penambangan timah dilaksanakan oleh tiga perusahaan, yaitu: Singkep Tin Exploitatie Maatschappij (NV SITEM) di Singkep, Banka Tin Winning Bedrijf (BTW) di Bangka, dan Gemeeenschappelijke Mijnbouw Maatschappij Billiton (GMB) di Belitung. Ketiga perusahaan ini kemudian dilebur menjadi salah satu Badan Usaha Milik Negara (BUMN) yang kini dikenal sebagai PT. Timah Tbk. PT. Kobatin pernah dikenal sebagai produsen timah terbesar kedua di Indonesia meskipun dinyatakan pailit dan ditutup pada tahun 2013 (Sabri, Aulia dan Novriyansyah, 2020). Perbandingan jumlah produksi PT. Timah Tbk. dan PT. Koba Tin terlampir pada Tabel 1.

Rekam penambangan timah Indonesia tidak terlepas dari harga pasar dunia yang dipengaruhi oleh pasokan (supply) dan permintaan (demand). Logam ini mendunia pada abad ke-19 dengan ditemukannya deposit raksasa di Bolivia, Nigeria, Afrika Selatan, Inggris Raya, Australia, Malaysia, Cina, Thailand, dan termasuk Indonesia. Pada masa tersebut, timah sangat dibutuhkan oleh dunia, terutama Eropa, yang berada dalam era industri untuk pembuatan kaleng, piring, gelas, wadah air, dan pelapis besi. Eksploitasi timah besar-besaran kemudian menciptakan kondisi over supply (kelebihan pasokan) yang menjatuhkan harga timah. Beberapa negara dengan sukarela mengurangi jumlah penambangan timah tahunan mereka pada 1930. Mekanisme tersebut dianggap gagal sehingga diadakan perjanjian International Tin Agreement (ITA) pertama yang ditandatangani oleh Malaysia, Nigeria, Hindia Belanda (sekarang Indonesia), dan Bolivia untuk bersama-sama menjaga pasokan timah dunia sehingga harga timah terjaga dalam kisaran yang pantas (Prest, 1986). Perjanjian tersebut juga menjadi cikal bakal pembentukan International Tin Council (ITC). Terdapat rentang waktu yang disetujui dan jumlah peserta yang dapat berubah pada perjanjian ITA.

Tabel 1. Jumlah produksi timah PT. Timah Tbk. dan PT.Koba Tin (ton) 1993 hingga 2002

\begin{tabular}{ccccccc}
\hline \multirow{2}{*}{ Tahun } & \multicolumn{2}{c}{ PT. Timah Tbk. } & \multicolumn{2}{c}{ PT. Koba Tin } & \multicolumn{2}{c}{ Total } \\
\cline { 2 - 6 } & Logam & Konsentrat & Logam & Konsentrat & Logam & Konsentrat \\
\hline 1993 & 26.465 & 28.349 & 7.616 & 10.152 & 34.081 & 38.501 \\
1994 & 35.686 & 33.981 & 7.916 & 10.556 & 43.962 & 44.537 \\
1995 & 37.416 & 38.829 & 7.079 & 9.416 & 44.495 & 48.245 \\
1996 & 40.337 & 42.143 & 8.428 & 11.305 & 48.765 & 53.448 \\
1997 & 42.620 & 44.105 & 10.416 & 14.055 & 53.036 & 58.160 \\
1998 & 43.418 & 43.714 & 10.247 & 13.848 & 53.665 & 57.562 \\
1999 & 39.030 & 39.030 & 10.679 & 14.685 & 49.709 & 53.715 \\
2000 & 35.550 & 37.076 & 11.579 & 15.604 & 47.129 & 52.680 \\
2001 & 38.081 & 40.050 & 15.715 & 21.328 & 53.796 & 61.378 \\
2002 & 43.528 & 55.038 & 23.927 & 33.104 & 67.455 & 88.142 \\
\hline
\end{tabular}

Sumber: Rochani dan Pramusanto (2010) 
Meskipun fluktuatif, harga timah tampak dapat lebih terjaga melalui rangkaian perjanjian ITA. Kejatuhan nilai jual timah pada pertengahan 1980-an (Gambar 2) disebabkan oleh beberapa faktor, yaitu kegagalan perjanjian ITA ke-6, hutang raksasa ITC, penemuan bahan substitusi, dan daur ulang timah (Chandrasekhar, 1989). Kemerosotan hasil eksploitasi timah dialami oleh para negara produsen timah utama dunia yang tergabung dalam pakta ITA ke-6, kecuali Indonesia. Pada sisi lain, produsen timah tradisional dunia yang lain, seperti Cina, Brazil, dan Bolivia dapat menaikkan produksi timahnya namun menolak untuk bergabung pada perjanjian ITA-6 1986 sehingga dengan bebas dapat memproduksi dan mengekspor timah. Pada akhir 1980-an terungkap bahwa ITC memiliki tunggakan hutang yang sangat besar dan tidak ada negara anggota yang mau bertangggugjawab. Oleh sebab itu, Indonesia harus belajar dari peristiwa tersebut agar dapat mengatur jumlah penjualan timah dengan bertolak pada kondisi pasar dan sepantasnya lebih aktif dalam memonitor setiap perjanjian yang diikutinya. Kebutuhan timah dunia pada periode ini semakin tergerus oleh pemakaian bahan pengganti timah, seperti plastik dan aluminium penyimpanan makanan. Beberapa negara importir timah juga menggalakkan program daur ulang timah yang menurunkan angka permintaan timah (Prest, 1986; Thoburn, 1994).

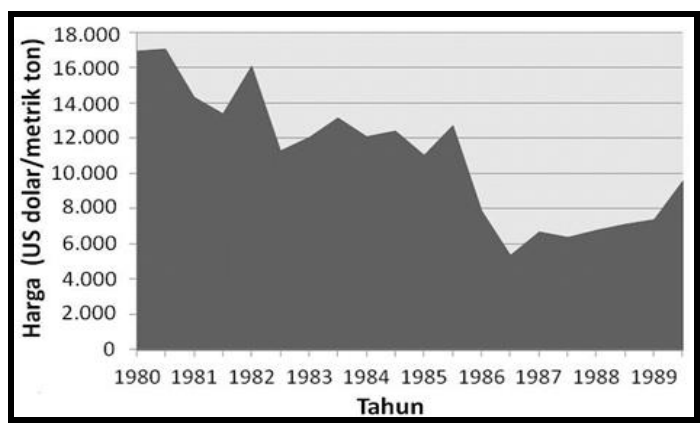

Gambar 2. Fluktuasi harga jual timah pada 1980an (Mongabay, 2020)

Bagi Indonesia, anjoknya harga timah tersebut memberi tekanan berat pada devisa negara. Meski Indonesia dapat menjaga kapasitas produksinya seperti telah dijelaskan di atas, kejatuhan harga timah mengurangi devisa negara secara signifikan. Produksi timah pada
1984 meningkat dari 23,3 kton menjadi 24 kton pada 1986, bahkan melonjak tinggi menjadi 32 kton di akhir 1989. Namun demikian, devisa negara jauh menurun dari USS 288 juta (1984) menjadi USS 129 juta (1986). Sempat menyumbang devisa negara sebanyak USD 237 juta pada 1989, fluktuasi harga timah membuat hasil penjualannya kembali turun ke USD 167 juta pada 1991 (Tabel 2).

Tabel 2. Produksi timah tahunan Indonesia pada periode 1980-1991 dan perkiraan devisanya

\begin{tabular}{cccc}
\hline Tahun & $\begin{array}{c}\text { Produksi } \\
\text { (kton) }\end{array}$ & $\begin{array}{c}\text { Harga timah } \\
\text { (USD/metrik ton) }\end{array}$ & $\begin{array}{c}\text { Devisa } \\
\text { (USD juta) }\end{array}$ \\
\hline 1980 & 32.5 & 17090 & 555,43 \\
1984 & 23.2 & 12442 & 288,65 \\
1986 & 24 & 5,386 & 129,26 \\
1989 & 32 & 9,605 & 237,09 \\
1991 & 29.4 & 5703 & 167,67 \\
\hline
\end{tabular}

Sumber: USGS (1981-1992)

\section{Timah Indonesia pada Dekade Terakhir}

Produksi tambang timah Indonesia tercatat setidaknya 40.000 ton/tahun selama satu dekade terakhir dengan rerata 60.500 ton/tahun (USGS, 2018). Hasil tambang timah Indonesia mencapai jumlah tertinggi pada 2018 (83.000 ton) dan terendah pada 2013 (40.000 ton). Indonesia mampu menjadi sumber logam timah dunia pada kisaran 17\%28\% dalam sepuluh tahun terakhir. Sejak 2011 hingga 2020, Indonesia hampir selalu tercatat sebagai produsen timah kedua terbesar di dunia setelah Cina kecuali pada 2016 (Gambar 3). Penambangan di Cina dan Burma secara berturut-turut dapat menghasilkan 92.000 ton dan 54.000 ton timah pada 2016, sedangkan Indonesia pada angka 52.000 ton. Peningkatan supply timah dari Burma tersebut terjadi akibat pengoperasian tambang baru di Wa State (Gardiner dkk., 2015).

Sebagian besar logam timah dari Nusantara diproduksi oleh PT Timah Tbk. Lebih dari 95\% timah Indonesia pada 2019 dihasilkan oleh Badan Usaha Milik Negara (BUMN) tersebut. PT Timah Tbk selalu menjadi tiga besar perusahaan produsen timah dunia pada periode 2013-2019 bersama Yunnan Tin (Cina) dan Malaysia Smelting Corp (Malaysia). 
Dengan produksi logam timah mencapai 76.400 ton pada 2019, PT Timah Tbk sempat menjadi pemasok timah terbesar dunia. Tingginya tingkat produksi PT Timah dapat dipertahankan karena pengalihan eksploitasi dari darat ke laut menggunakan kapal keruk dan kapal hisap (Gambar 4a dan 4b) dengan slogan 'go offshore, go deeper'. Kemudian, sumber logam timah dari BUMN ini juga berasal dari material daur ulang yang diperoleh dari pabrik peleburan bijih timah selain dari hasil eksploitasi darat maupun laut. Kebijakan ini sesuai untuk dilanjutkan berdasarkan fakta bahwa $>90 \%$ cadangan terbukti timah pada wilayah IUP PT Timah Tbk terdapat di laut (PT Timah Tbk, 2020).

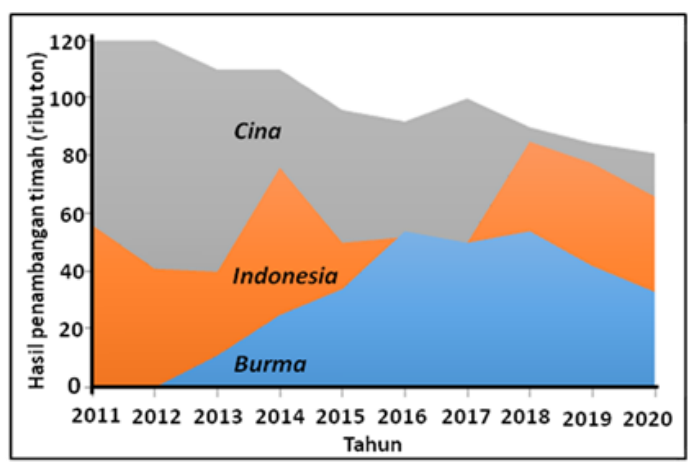

Gambar 3. Perbandingan produksi timah dari Cina, Indonesia, dan Burma selama 2011 hingga 2020 (Mulqueen, 2018; USGS, 2020).

Fluktuasi jumlah produksi, penjualan, dan cadangan dari PT Timah dapat diperhatikan pada Gambar 5. Pada umumnya pendapatan sangat dipengaruhi harga timah dan nilai tukar mata uang terhadap dolar terhadap rupiah. Namun demikian, korelasi ini tidak selalu linear dalam dunia pertambangan (Boubakri, Guillaumin dan Silanine, 2019). Total 363.113 ton logam timah telah dijual oleh PT Timah Tbk pada rentang 2011-2020 dengan rerata 36.3111 ton/tahun. Pendapatan (revenue) dari penjualan logam timah pada rentang waktu tersebut adalah Rp. 98,56 triliun. Namun demikian, jumlah penjualan tidak selalu berbanding lurus dengan pendapatan. Sejumlah 34.934 ton timah telah terjual pada 2012 dengan pendapatan Rp.7,83 triliun, sedangkan pada 2017 Perseroan mampu membukukan pendapatan Rp. 9,22 triliun meski dengan penjualan 29.914 ton. Seiring dengan perkembangan dunia dan pergerakan ekonomi global, maka tantangan yang harus dihadapi oleh perusahaan penambangan timah juga semakin kompleks. Oleh sebab itu, PT. Timah Tbk. terus meningkatkan sisi kolaborasi dan inovasi untuk pengembangan bisnisnya selama dekade terakhir. Sistem holding pertambangan melalui kerjasama di bidang pemasaran, pengadaan barang dan jasa, serta sinergi teknologi informasi merupakan aspek kolaborasi yang ditempuh. Inovasi yang diambil berupa penerapan teknologi mutakhir dalam operasional penambangan di antaranya adalah Bore Hole Mining (BHM), Fuming and Ausmelt, dan Management Information System (MIS) terintegrasi. Perseroan bahkan telah menjajaki kemungkinan ekspansi tambang di wilayah Afrika, khususnya Nigeria, namun terhambat akibat kebijakan lockdown pemerintah negara tersebut akibat wabah Covid-19 (PT Timah Tbk, 2020).
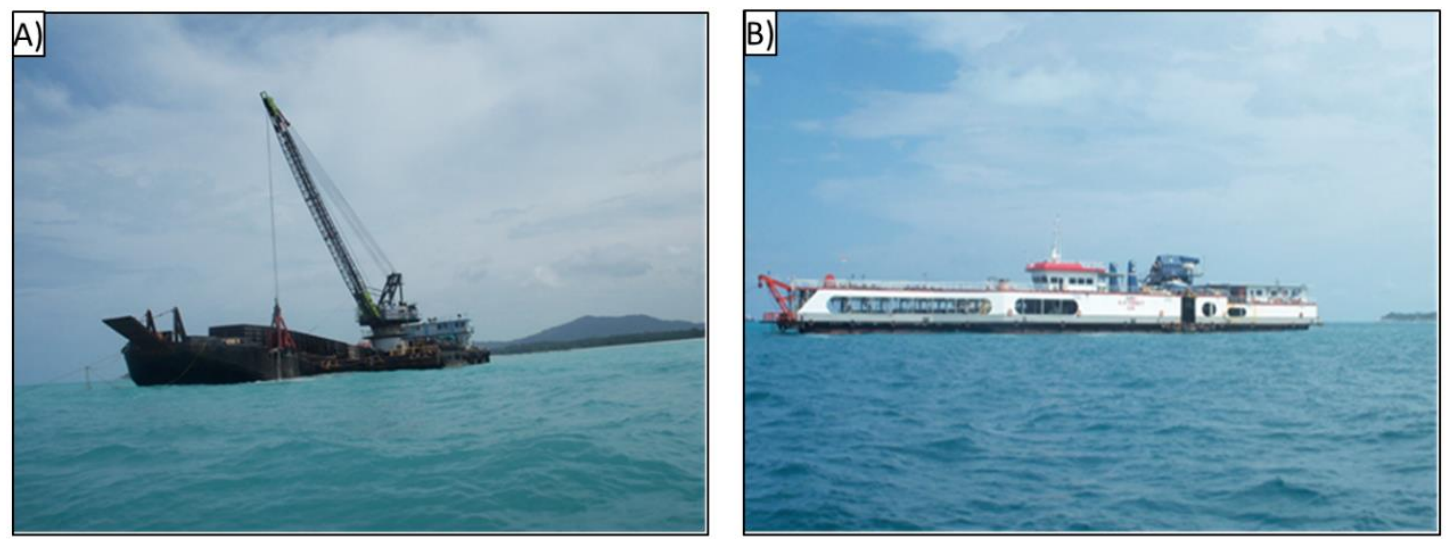

Gambar 4. Armada kapal milik PT Timah Tbk untuk eksploitasi di perairan Bangka dan Belitung: a) kapal keruk; dan b) kapal hisap. 


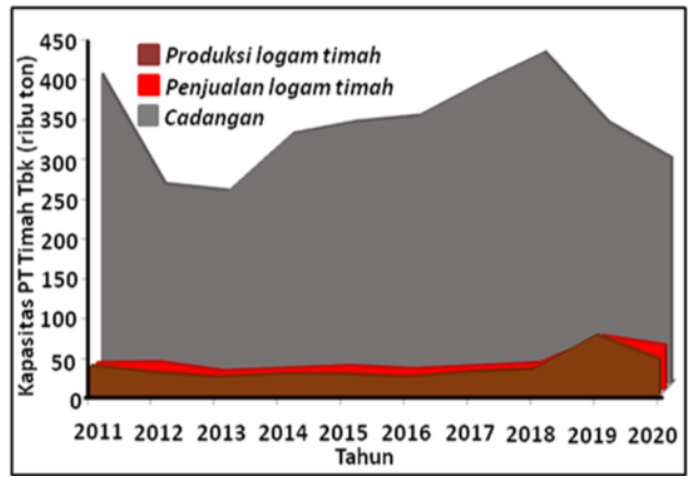

Gambar 5. Produksi, penjualan, dan cadangan PT Timah Tbk sejak 2011 hingga 2020 (PT Timah Tbk, 2021)

Harga sebuah komoditas dikendalikan oleh tingkat permintaan dan persediaan. Sekitar $60 \%$ produksi dan $>40 \%$ cadangan timah dunia berasal dari Cina dan Indonesia. Cina diketahui sebagai tiga besar pemberi hutang kepada Indonesia. Oleh sebab itu, harga jual timah diperkirakan juga tergantung pada tingkat suku bunga dan hubungan bilateral Indonesia-Cina (Munandar dkk., 2019). Meskipun Indonesia merupakan produsen timah besar dunia, $>98 \%$ hasilnya untuk ekspor dan kurang dari 2\% untuk kebutuhan domestik (PT Timah Tbk, 2020). Kondisi berbeda terjadi di Cina yang bahkan sejak 2015 menjadi importir timah meskipun merupakan produsen timah terbesar dunia (Yang dkk., 2018). Kondisi tersebut mengakibatkan kerugian bagi negara eksportir timah namun menjadi keuntungan untuk negara importir timah ketika terjadi penurunan harga global. Sistem holding pertambangan yang dijelaskan pada bagian sebelumnya juga dimaksudkan untuk mendorong penyerapan produk timah Indonesia oleh industri domestik.

\section{PELUANG PADA MASA MENDATANG}

Pada era modern timah diperlukan untuk pembuatan kaleng, baterai, pigmen, bahan konstruksi, alat transportasi, dan solder (Suprapto, 2008; Kamilli, Kimball dan Carlin, 2017; Yang $d k k$., 2018). Meskipun Cina merupakan produsen utama dunia, negara tersebut juga menjadi konsumen timah terbesar dunia selama dekade terakhir. Cina mengambil sekitar $40 \%$ dari total konsumsi tahunan timah dunia. Kebutuhan timah Cina dan dunia terutama untuk solder yang dipakai luas pada industri elektronik, proses pelekatan logam dan perpipaan. Cicuit board pada komputer, telepon genggam, dan panel-panel elektrik lainnya sangat membutuhkan solder yang terutama berbahan timah. Industri perpipaan juga semakin maju akibat kebutuhan pengaliran air bersih yang semakin meningkat (Thoburn, 1994; Yang $d k k ., 2018$ ). Oleh sebab itu, timah masih akan menjadi komoditi penting pada masa mendatang.

Komoditas pertambangan, termasuk timah, terkena dampak dari wabah Covid-19 sejak trimester pertama 2020 (Laing, 2020). Kebijakan lockdown di berbagai negara pada awal pandemi diperkirakan sebagai penyebab turunnya harga timah hingga menyentuh USD 13.400/ton. Namun demikian, harga timah terus meningkat sejak pertengahan 2020 hingga mencapai USD 26.000/ton untuk Februari 2021. Harga ini bahkan tertinggi sejak permulaan 2012. Pemodelan WORLD6 digunakan pada penelitian sebelumnya yang menyatakan bahwa nilai pasar timah akan mencapai tingkat tertinggi pada 2100 sebesar USD 60.000/ton (Olafsdottir dan Sverdrup, 2018).

Selain timah daur ulang, beberapa mineral ekonomis dapat ditemukan pada limbah penambangan timah. Monasit, zirkon, senotim, garnet, dan ilmenit adalah mineralmineral pembawa unsur tanah jarang (UTJ) yang ditemukan pada beberapa lokasi pembuangan tailing timah (Ali, 2014; Jonglertjunya, Rattanaphan dan Tipsak, 2014; Hamzah, Mardhiansyah dan Firdaus, 2018; Annisa Ummaradiah, Yusuf dan Mukiat, 2020). Mineral-mineral tersebut berharga lebih mahal daripada timah karena penggunaannya yang sangat luas dalam teknologi modern seperti mobil listrik, telepon genggam, radar, Magnetic Resonance Imaging (MRI), katalis, dan komputer. Selain UTJ, monasit juga terdiri dari unsur thorium yang dapat dimanfaatkan dalam pembangkit listrik (Ngadenin dkk., 2014; Olise $d k k ., 2014$; Subagja, 2014). Tailing penambangan timah di Nudur, Pulau Bangka, juga terbukti mengandung titanit dengan komposisi $\mathrm{TiO}_{2}$ yang tinggi (Irzon, Kurnia dan Haryanto, 2020). Ragam mineral yang mungkin terdapat pada pertambangan timah tertera pada Tabel 3. 
Tabel 3. Mineral-mineral yang teridentifikasi pada limbah penambangan timah

\begin{tabular}{|c|c|c|c|}
\hline Mineral & Formula & $\begin{array}{c}\text { Specific Gravity } \\
\text { (kg/liter) }\end{array}$ & $\begin{array}{c}\begin{array}{c}\text { Kekerasan } \\
\text { (Mohs) }\end{array} \\
\end{array}$ \\
\hline Monasit & $(\mathrm{Ce}, \mathrm{La}, \mathrm{Nd}, \mathrm{Th}) \mathrm{PO}_{4}$ & $4,9-5,5$ & 5,5 \\
\hline Senotim & $\mathrm{YPO}_{4}$ & $4,45-4,59$ & 4,5 \\
\hline Ilmenit & $(\mathrm{Fe}, \mathrm{Mg}, \mathrm{Mn}, \mathrm{Ti}) \mathrm{O}_{3}$ & $4,70-4,79$ & 5 to 6 \\
\hline Zirkon & $\mathrm{ZrSiO}_{4}$ & $4,6-4,7$ & 6 to 7,5 \\
\hline Titanit & $\begin{array}{l}\mathrm{CaTiSiO} 5 \\
\mathrm{X}_{3} \mathrm{Z}_{2}\left(\mathrm{SiO}_{4}\right)_{3}\end{array}$ & $3,48-3,60$ & 5 to 5,5 \\
\hline Kelompok Garnet & $\begin{array}{l}\mathrm{X}=\mathrm{Ca}, \mathrm{Fe}^{2+}, \mathrm{Mn}, \text { or } \mathrm{Mg} \\
\mathrm{Z}=\mathrm{Al}, \mathrm{Cr}, \text { or } \mathrm{Fe}^{3+}\end{array}$ & $3,1-4,3$ & $6,5-7,5$ \\
\hline
\end{tabular}

Sumber: Olise dkk. (2014); Kinnaird, Nex dan Milani (2016); Virgiawan dan Pitulima (2019); Irzon, Kurnia dan Haryanto (2020)

Keterdapatan mineral ikutan timah tersebut telah disadari oleh beberapa perusahaan besar dunia. Benefisiasi unsur tanah jarang (UTJ) dari limbah timah dimulai oleh perusahaanperusahaan besar dunia seperti Lynas Corp (Malaysia dan Australia), Molycorp Inc. (Amerika Serikat), dan Malaysian Rare Earth Corporation (Malaysia) sejak akhir abad ke-20 (Sulaiman, 1991; Ali, 2014). PT Timah juga telah menyadari prospek yang terdapat pada residu pengolahan timah dan membangun Unit Metalurgi Muntok di Tanjung Ular, Kabupaten Bangka Barat (Virgiawan dan Pitulima, 2019). Pengolahan limbah timah juga mengurangi dampak lingkungan yang disebabkan oleh penambangan agar sejalan dengan Undang-Undang No. 3 Tahun 2020.

\section{KESIMPULAN DAN SARAN}

Meskipun pada awalnya berhasil menjaga stabilitas timah dunia, ITA dan ITC dianggap sebagai penyebab kejatuhan harga pada pertengahan 1980-an. Berkaca pada kegagalan ITA dan ITC yang menjadi penyebab kejatuhan harga timah tersebut, Indonesia jangan cepat tergoda untuk turut bergabung dalam suatu perjanjian internasional, terutama terkait dengan sumberdaya yang dikuasai Indonesia secara global. Ketidaktepatan dalam mengambil keputusan dapat membuat sumberdaya yang berasal dari bumi Nusantara justru dikendalikan pihak lain. Berstatus sebagai produsen timah besar dunia, Indonesia harus lebih cerdas dalam mengelola sumberdaya alamnya dan terus mendorong agar PT Timah Tbk dapat menjadi perusahaan kelas dunia. Kebijakan pengalihan konsentrasi eksploitasi oleh PT Timah Tbk dari darat ke laut dianggap cocok berdasarkan jumlah cadangan terbukti di laut yang mencapai $>90 \%$. Pemerintah harus mendorong penyerapan produksi timah nasional oleh industri domestik sebagai antisipasi penurunan harga global pada masa mendatang. Timah diproyeksikan sebagai komoditas penting pada masa mendatang dengan harga jual yang meningkat. Indonesia harus mampu memanfaatkan mineral-mineral dalam limbah timah untuk peningkatan pendapatan, pembangkit energi, dan mengurangi dampak negatif pertambangan.

\section{UCAPAN TERIMA KASIH}

Penulis mengucapkan terima kasih kepada Kepala Pusat Survei Geologi atas bantuannya dalam penyelesaian tulisan ini. PT. Timah Tbk telah banyak membantu penulis selama kegiatan lapangan di darat maupun perairan Bangka dan Belitung. Apresiasi ditujukan atas kontribusi Bapak Purnama Sendjaja, Bapak Kurnia, dan Bapak Verry Edy Setiawan mengenai geologi dan pertambangan.

\section{DAFTAR PUSTAKA}

Ali, S. (2014) "Social and environmental impact of the rare earth industries," Resources, 3(1), hal. 123-134. doi: 10.3390/resources3010123.

Annisa Ummaradiah, Yusuf, M. dan Mukiat (2020) "Potensi investasi peningkatan nilai tambah mineral ikutan timah di Kepulauan Bangka Belitung," Jurnal Pertambangan, 4(2), hal. 98-107. doi: 10.36706/jp.v4i2.469.

Boubakri, S., Guillaumin, C. dan Silanine, A. (2019) "Non-linear relationship between real commodity price volatility and real effective exchange rate: The case of commodity- 
exporting countries," Journal of Macroeconomics, 60, hal. 212-228. doi: 10.1016/j.jmacro.2019.02.004.

Breitfeld, H. T., Hennig-Breitfeld, J., BouDagherFadel, M. K., Hall, R. dan Galin, T. (2020) "Oligocene-Miocene drainage evolution of NW Borneo: Stratigraphy, sedimentology and provenance of Tatau-Nyalau province sediments," Journal of Asian Earth Sciences, 195, hal. 104331.

doi: 10.1016/j.jseaes.2020.104331.

Cairncross, B. (2020) "The where of mineral names: Nigerite (now ferronigerite-2N1S) Egbe District, Kogi State, Nigeria," Rocks \& Minerals, 95(4), hal. 377-379.

doi: 10.1080/00357529.2020.1744102.

Chandrasekhar, S. (1989) "Cartel in a can: The financial collapse of the international tin council," Northwestern Journal of International Law \& Business, 10(2), hal. 309-332.

Cheng, Y., Spandler, C., Chang, Z. dan Clarke, G. (2018) "Volcanic-plutonic connections and metal fertility of highly evolved magma systems: A case study from the Herberton SnW-Mo Mineral Field, Queensland, Australia," Earth and Planetary Science Letters, 486, hal. 84-93. doi: 10.1016/j.epsl.2018.01.012.

Clarke, M. C. G. dan Beddoe-Stephens, B. (1987) "Geochemistry, mineralogy and plate tectonic setting of a Late Cretaceous Sn-W Granite from Sumatra, Indonesia," Mineralogical Magazine, 51(361), hal. 371-387. doi: 10.1180/minmag. 1987.051.361.04.

Gardiner, N. J., Sykes, J. P., Trench, A. dan Robb, L. J. (2015) "Tin mining in Myanmar: Production and potential," Resources Policy, 46, hal. 219233. doi: 10.1016/j.resourpol.2015.10.002.

Hamzah, Y., Mardhiansyah, M. dan Firdaus, L. N. (2018) "Characterization of rare earth elements in tailing of ex-tin mining sands from Singkep Island, Indonesia," Aceh International Journal of Science and Technology, 7(2), hal. 131-137. doi: 10.13170/aijst.7.2.8622.

Irzon, R., Sendjadja, P., Kurnia, Imtihanah dan Soebandrio, J. (2014) "Kandungan rare earth elements dalam tailing tambang timah di Pulau Singkep," Jurnal Geologi dan Sumberdaya Mineral, 15(3), hal. 143-151.

Irzon, R. (2017) "Geochemistry of late triassic weak peraluminous A-type Karimun Granite, Karimun Regency, Riau Islands Province,"
Indonesian Journal on Geoscience, 4(1), hal. 21-37. doi: 10.17014/ijog.4.1.21-37.

Irzon, R., Syafri, I., Hutabarat, J., Sendjaja, P. dan Permanadewi, S. (2018) "Heavy metals content and pollution in tin tailings from Singkep Island, Riau, Indonesia," Sains Malaysiana, 47(11), hal. 2609-2616. doi: 10.17576/jsm-2018-4711-03.

Irzon, R. (2018) "Limbah pencucian bauksit sebagai sumber unsur tanah jarang potensial; studi kasus Pulau Selayar, Provinsi Kepulauan Riau," Buletin Sumber Daya Geologi, 13(1), hal. 45-57. doi: 10.47599/bsdg.v13i1.63.

Irzon, R., Kurnia dan Haryanto, A. (2020) "Presisi pengukuran produk samping tambang timah nudur menggunakan analisis XRF dan peluang ekonomi produknya," Jurnal Teknologi Mineral dan Batubara, 16(2), hal. 69-79. doi: 10.30556/jtmb.Vol16.No2.2020.1089.

Johari, S. dan Umi, K. (1991) "The occurences of rare earth minerals in Indonesia," Materials Science Forum, 70-72, hal. 645-0. doi: 10.4028/www.scientific.net/MSF.70-72.645.

Jonglertjunya, W., Rattanaphan, S. dan Tipsak, P. (2014) "Kinetics of the dissolution of ilmenite in oxalic and sulfuric acid solutions," AsiaPacific Journal of Chemical Engineering, 9(1), hal. 24-30. doi: 10.1002/apj.1742.

Kamilli, R. J., Kimball, B. E. dan Carlin, J. F. J. (2017) "Tin," in Schulz, K. J. et al. (ed.) Critical mineral resources of the United States-Economic and environmental geology and prospects for future supply. Reston, VA: U.S. Geological Survey, hal. S1-S53. doi: 10.3133/PP1802S.

Kinnaird, J. A., Nex, P. A. M. dan Milani, L. (2016) "Tin in Africa," Episodes, 39(2), hal. 361-380. doi: 10.18814/epiiugs/2016/v39i2/95783.

Laing, T. (2020) "The economic impact of the Coronavirus 2019 (Covid-2019): Implications for the mining industry," The Extractive Industries and Society, 7(2), hal. 580-582. doi: 10.1016/j.exis.2020.04.003.

Mongabay (2020) Price of tin, (1980-2010) price chart, www.mongabay.com. Tersedia pada: https://data.mongabay.com/commodities/pric e-charts/tin-price.html.

Mulqueen, T. (2018) "Tin market outlook: A trade storm is brewing. Will tin survive?," in 2018 Asia Tin Summit, Shenzhen. International Tin Association. Tersedia pada: 
https://www.internationaltin.org/wpcontent/uploads/2018/09/1.2-Tin-MarketOutlook-International-Tin-Association.pdf.

Munandar, A. I., Siregar, H., Andati, T. dan Anggraeni, L. (2019) "Price determinant of tin price.," Journal of Economic \& Management Perspectives, 13(4), hal. 33-40.

Ngadenin, Syaeful, H., Widana, K. S. dan Nurdin, M. (2014) "Potensi thorium dan uranium di Kabupaten Bangka Barat," Eksplorium, 35(2), hal. 69-84.

Olafsdottir, A. H. dan Sverdrup, H. U. (2018) "Modelling global mining, secondary extraction, supply, stocks-in-society, recycling, market price and resources, using the WORLD6 Model; tin," BioPhysical Economics and Resource Quality, 3(3), hal. 11. doi: 10.1007/s41247-018-0041-8.

Olise, F. S., Oladejo, O. F., Almeida, S. M. Owoade, O. K., Olaniyi, H. B. dan Freitas, M. C. (2014) "Instrumental neutron activation analyses of uranium and thorium in samples from tin mining and processing sites," Journal of Geochemical Exploration, 142, hal. 36-42. doi: 10.1016/j.gexplo.2014.01.004.

Pollard, P. J., Nakapadungrat, S. dan Taylor, R. G. (1995) "The Phuket Supersuite, Southwest Thailand; fractionated I-type granites associated with tin-tantalum mineralization," Economic Geology, 90(3), hal. 586-602. doi: 10.2113/gsecongeo.90.3.586.

Powell, W., Yazgan, E., Johnson, M., Yener, K. A. dan Mathur, R. (2021) "Mineralogical analysis of the Kestel Mine: An early bronze age source of tin ore in the Taurus Mountains, Turkey," Minerals, 11(1), hal. 91. doi: 10.3390/min 11010091 .

Prest, M. (1986) "The collapse of the international tin agreement," IDS Bulletin, 17(4), hal. 1-8. doi: $10.1111 / \mathrm{j} .1759$ 5436.1986.mp17004006.x.

PT Timah Tbk (2020) Laporan tahunan terintegrasi: Opportunity in uncertainty. Tangerang.

PT Timah Tbk (2021) Annual Report PT TIMAH TBK. Jakarta. Tersedia pada: https://timah.com/blog/report/annualreport.ht $\mathrm{ml}$.

Qiu, Z., Yan, Q., Li, S., Wang, H., Tong, L., Zhang, R., Wei, X., Li, P., Wang, L., Bu, A. dan Yan, L. (2017) "Highly fractionated Early Cretaceous Itype granites and related $\mathrm{Sn}$ polymetallic mineralization in the Jinkeng deposit, eastern
Guangdong, SE China: Constraints from geochronology, geochemistry, and $\mathrm{Hf}$ isotopes," Ore Geology Reviews, 88, hal. 718738. doi: 10.1016/j.oregeorev.2016.10.008.

Qu, Q., Liu, G., Henry, M., Point, D., Chmeleff, J., Sun, R., Sonke, J. E. dan Chen, J. (2020) "Tin stable isotopes in magmatic-affected coal deposits: Insights in the geochemical behavior of tin," Applied Geochemistry, 119, hal. 104641.

doi: 10.1016/j.apgeochem.2020.104641.

Rochani, S. dan Pramusanto (2010) Timah di Indonesia (Sumber dan pemanfaatan). Bandung: Puslitbang tekMIRA.

Rosyida, I., Ullah, W., Helmi, A. dan Sasaoka, M. (2019) "Adapting livelihoods to the impacts of tin mining in Indonesia: Options and constraints," The Extractive Industries and Society. Elsevier, 6(4), hal. 1302-1313. doi: 10.1016/j.exis.2019.10.018.

Sabri, F., Aulia, T. dan Novriyansyah, M. (2020) Inventarisasi dan model pemanfaatan Kulong di Bangka Belitung. Yogyakarta: Deepublish Publisher.

Subagja, R. (2014) "Monasite Bangka dan alternatif proses pengolahannya," Metalurgi, 29(1), hal. 79-90. doi: 10.14203/metalurgi.v29i1.274.

Sulaiman, M. Y. (1991) "An overview of the rareearth mineral processing industry in Malaysia," Materials Science Forum, 70-72, hal. 389396. doi: 10.4028/www.scientific.net/MSF.7072.389 .

Suprapto, S. J. (2008) "Potensi, prospek dan pengusahaan timah putih di Indonesia," Buletin Sumber Daya Geologi. Pusat Sumber Daya Mineral Batubara dan Panas Bumi, 3(2), hal. 4-15. doi: 10.47599/bsdg.v3i2.158.

Syahrir, R., Wall, F. dan Diallo, P. (2020) "Socioeconomic impacts and sustainability of mining, a case study of the historical tin mining in Singkep Island-Indonesia," The Extractive Industries and Society, 7(4), hal. 1525-1533. doi: 10.1016/j.exis.2020.07.023.

Thoburn, J. T. (1994) "The tin industry since the collapse of the International Tin Agreement," Resources Policy, 20(2), hal. 125-133. doi: 10.1016/0301-4207(94)90025-6.

USGS (2018) Mineral commodity summaries 2018. Reston, Virginia. Tersedia pada: https://minerals.usgs.gov/minerals/pubs/mcs/2 018/mcs2018.pdf. 
USGS (2020) Mineral commodity summaries. Reston, VA: U.S. Geological Survey. doi: 10.3133/MCS2020.

Virgiawan, M. R. dan Pitulima, J. (2019) “Technical evaluation of associated tin minerals processing at Bidang Pengolahan Mineral (BPM) Unit Metalurgi Muntok, PT Timah Tbk," IOP Conference Series: Earth and Environmental Science, 353(1), hal. 012043. doi: 10.1088/1755-1315/353/1/012043.
Wicaksono, H. M. H. dan Handayani, E. (2021) "Karakterisasi mineralogi mineral berbasis $\mathrm{Cu}$ Fe-S dengan SEM EDS di daerah Kelapa Kampit, Pulau Belitung," Jurnal Teknologi Mineral dan Batubara, 17(1), hal. 27-38. doi: 10.30556/jtmb.Vol17.No1.2021.1127.

Yang, C., Tan, Q., Zeng, X., Zhang, Y., Wang, Z. dan $\mathrm{Li}$, J. (2018) "Measuring the sustainability of tin in China," Science of The Total Environment, 635, hal. 1351-1359. doi: 10.1016/j.scitotenv.2018.04.073. 